\title{
Seasonal variations of 3.0 3.8-day ultra-fast Kelvin waves observed with a meteor wind radar and radiosonde in Indonesia
}

\author{
S. Yoshida, T. Tsuda, A. Shimizu, and T. Nakamura
}

Radio Atmospheric Science Center, Kyoto University, Kyoto 611-0011, Japan

(Received August 17, 1998; Revised March 5, 1999; Accepted March 5, 1999)

\begin{abstract}
This paper is concerned with observations of the long-term behavior of Kelvin waves with the wave period ranging from 3 to 4 days, which are generally called an ultra-fast Kelvin (UFK) wave. Horizontal wind velocity at $74-110 \mathrm{~km}$ altitudes observed with a meteor wind radar (MWR) near Jakarta $\left(6.4^{\circ} \mathrm{S}, 106.7^{\circ} \mathrm{E}\right)$ for five years during November 1992 and December 1997 and daily radiosonde profiles in Bandung $\left(6.9^{\circ} \mathrm{S}, 107.6^{\circ} \mathrm{E}\right)$ collected between October 1993 and March 1996 and have been analyzed. In the mesosphere and lower thermosphere (MLT) region, the UFK wave activity, defined by the spectral density of zonal wind perturbations at the 3.0-3.8 day period, is strongly enhanced twice a year. An interaction between UFK waves and a semiannual oscillation in the mesosphere (MSAO) can be suggested, although an exact mechanism is uncertain. We also have investigated seasonal variation of 3.0-3.8 day oscillations of zonal winds in the stratosphere, excluding gravity wave components, but, we have not detected an evidence of semiannual periodicity. The UFK wave activity in the MLT region exhibited intraseasonal variations, which showed some correlation with the amplitudes of zonal wind in the troposphere.
\end{abstract}

\section{Introduction}

Extensive observations of the equatorial atmosphere dynamics have been carried out in the last several decades by means of a balloon or rocket-borne equipment, ground-based radars as well as satellite measurements. Furthermore, a number of theoretical studies have also been continued, by employing a mechanistic model and a GCM. As a result, it has now become commonly recognized that convection and various atmospheric waves in equatorial regions play an important role in maintaining the global atmospheric circulation of the middle atmosphere.

The lower stratosphere in an equatorial region is characterized by predominance of a quasi-biennial oscillation (QBO) which was first reported by Ebdon (1960). A semiannual oscillation (SAO) becomes evident in the upper stratosphere (Reed, 1962), which is called stratospheric SAO (SSAO). Groves (1972) further found SAO in the mesosphere (mesospheric SAO, MSAO), which is phase-reversed relative to SSAO.

The character of Kelvin waves correspond to the eastward propagating disturbance with a global zonal structure. Existence of an equatorial Kelvin wave in the tropical middle atmosphere was first identified by Wallace and Kousky (1968a). Thus, the fundamental mode of Kelvin waves in the lower stratosphere is named as the Wallace and Kousky wave, which is characterized by the eastward wavenumber 1 with the wave period of 10-20 days. This wave is also called as a slow Kelvin wave, and it is hereafter designated as SK. Second type of Kelvin waves, characterized by the eastward wavenumber of 1 with the wave period of 7-10 days, was

Copy right(C) The Society of Geomagnetism and Earth, Planetary and Space Sciences (SGEPSS); The Seismological Society of Japan; The Volcanological Society of Japan; The Geodetic Society of Japan; The Japanese Society for Planetary Sciences. first detected by Hirota $(1978,1979)$ by analyzing rocketsonde and satellite observations in the upper stratosphere. This wave is called a fast Kelvin (FK) wave.

Kelvin waves are unique in transporting only eastward momentum, so, they are thought to play a key role in wave mean flow interactions. Another important source of momentum flux in tropics, but to the opposite direction, is mixed Rossbygravity (MRG) waves, first reported by Yanai and Maruyama (1966). Assuming an alternating momentum deposition by SK and MRG waves, causing eastward and westward acceleration, respectively, Holton and Lindzen (1972) proposed a theory to describe a generation mechanism of QBO. Recent studies, however, suggested that additional momentum deposition by gravity waves is necessary to quantitatively explain the behavior of QBO (e.g., Dunkerton, 1997). On the other hand, FK waves seem to be a major source driving the stratospheric semiannual oscillation (SSAO) (e.g., Dunkerton, 1979; Hitchman and Leovy, 1988).

The long-term behavior of both SK and FK waves has been widely investigated. Activity of SK wave becomes vigorous when the QBO rapidly changes the wind direction from westward to eastward (Wallace and Kousky, 1968b; Maruyama, 1969; Devarajan et al., 1985; Shiotani and Horinouchi, 1993). Large amplitudes of FK waves coincide with the westward phase of SSAO (Hirota, 1978).

In addition to SK and FK waves, Salby et al. (1984) reported a third category of Kelvin waves in the mesosphere and lower thermosphere (MLT), having a wave period of 3-4 day, which is called the ultra-fast Kelvin (UFK) wave. It was reported that UFK wave activity in the MLT region showed a semiannual variation (Vincent, 1993). Hirota (1978) found the existence of weak wind region at 60-70 km, which seems to effectively separate MSAO from SSAO. It is suggested, therefore, that the driving sources are also different between 


\section{Observation Periods of MWR (Jakarta, $6^{\circ} \mathrm{S}$ ) and SONDE (Bandung, $7^{\circ} \mathrm{S}$ )}

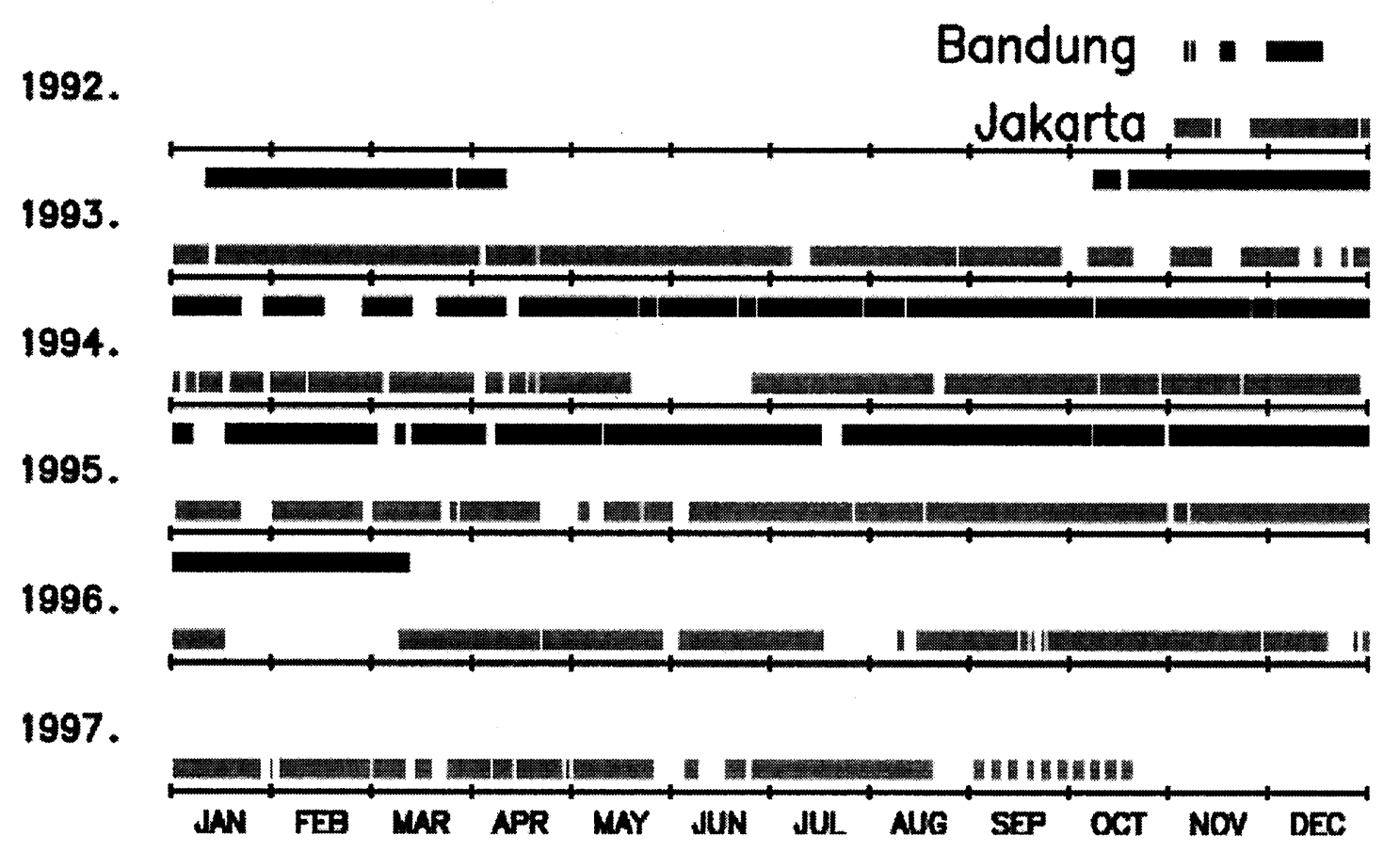

Fig. 1. Observation periods of the MWR in Jakarta $\left(6.4^{\circ} \mathrm{S}, 106.7^{\circ} \mathrm{E}\right)$ (bottom), radiosondes in Bandung $\left(6.90^{\circ} \mathrm{S}, 107.6^{\circ} \mathrm{E}\right)$ (top).

SSAO and MSAO, and that UFK is expected to be a driving force of MSAO, considering an analogy of a relation between FK and SSAO.

Riggin et al. (1997) recently investigated in detail the vertical structure and propagation characteristics of UFK, using a campaign observation with a meteor wind radar (MWR) near Jakarta $\left(6.4^{\circ} \mathrm{S}, 106.7^{\circ} \mathrm{E}\right)$ and an MF radar in Christmas Island $\left(2^{\circ} \mathrm{N}, 157^{\circ} \mathrm{E}\right)$. By comparing the results between the two sites, the zonal momentum flux and eastward accelation due to UFK wave was estimated, and it was demonstrated that distinct differences were observed in the UFK wave characteristics at the two sites.

As an extension of a case study by Riggin et al. (1997), we study in this paper the long-term variations of UFK waves in the MLT region, analyzing a large amount of data-sets collected with MWR at Jakarta in 1992-1997. We also investigate daily radiosonde profiles at Bandung in 1993-1996 in order to detect UFK waves in the lower atmosphere.

Section 2 of this paper covers a brief explanation of the MWR system and the radiosonde observations. Section 3 indicates the long-term behavior of the mean winds in the MLT region observed with MWR. In Section 4 we apply a spectral analysis on the MWR data, and discuss the seasonal variation of the UFK intensity in the MLT region, comparing the characteristics with the MSAO structure. In Section 5, we refer to the radiosonde profiles, and discuss the behavior of Kelvin waves and activity of convection in the troposphere and lower stratosphere.

\section{Observations with MWR and Radiosonde 2.1 Data-sets}

In collaboration with Indonesian research institutes we have been operating MWR in a radar observatory near Jakarta (6.4 $\left.{ }^{\circ} \mathrm{S}, 106.7^{\circ} \mathrm{E}\right)$ since November 1992 (Tsuda et al., 1995). The Jakarta MWR is a pulse modulated monostatic Doppler radar, operated at a central frequency of $31.57 \mathrm{MHz}$. Radial winds for meteor trails are measured at $74-110 \mathrm{~km}$ with a height resolution of $4 \mathrm{~km}$. Horizontal wind velocity is inferred every $1-4$ hours, by using a least square fit. The meteor echo rate shows a diurnal variation with a maximum at about $6 \mathrm{LT}$, and the height distribution can be approximated by a Gaussian with the mean and s.d. of $92 \mathrm{~km}$ and $7 \mathrm{~km}$, respectively. Some data gaps are found late afternoon at high and low ends of the altitude range.

In association with the radar measurements, radiosonde experiments were conducted at the LAPAN observatory in Bandung $\left(6.9^{\circ} \mathrm{S}, 107.6^{\circ} \mathrm{E}\right)$. We observed horizontal winds, pressure, temperature at $0-38 \mathrm{~km}$, and relative humidity below about $10 \mathrm{~km}$. Obtained data are averaged every $150 \mathrm{~m}$. An intensive campaign was carried out between November 1992 and April 1993, launching four radiosondes per day (Tsuda et al., 1995; Shimizu and Tsuda, 1997). In addition, a daily radiosonde sounding at 7 LT (0 UT) was commenced in October 1993, and it was continued until March 1996.

We present in Fig. 1 observation periods of MWR and radiosondes. We employ these data-sets for a study of the climatological behavior of the equatorial atmosphere dynamics in the MLT region and lower atmosphere, with a special 


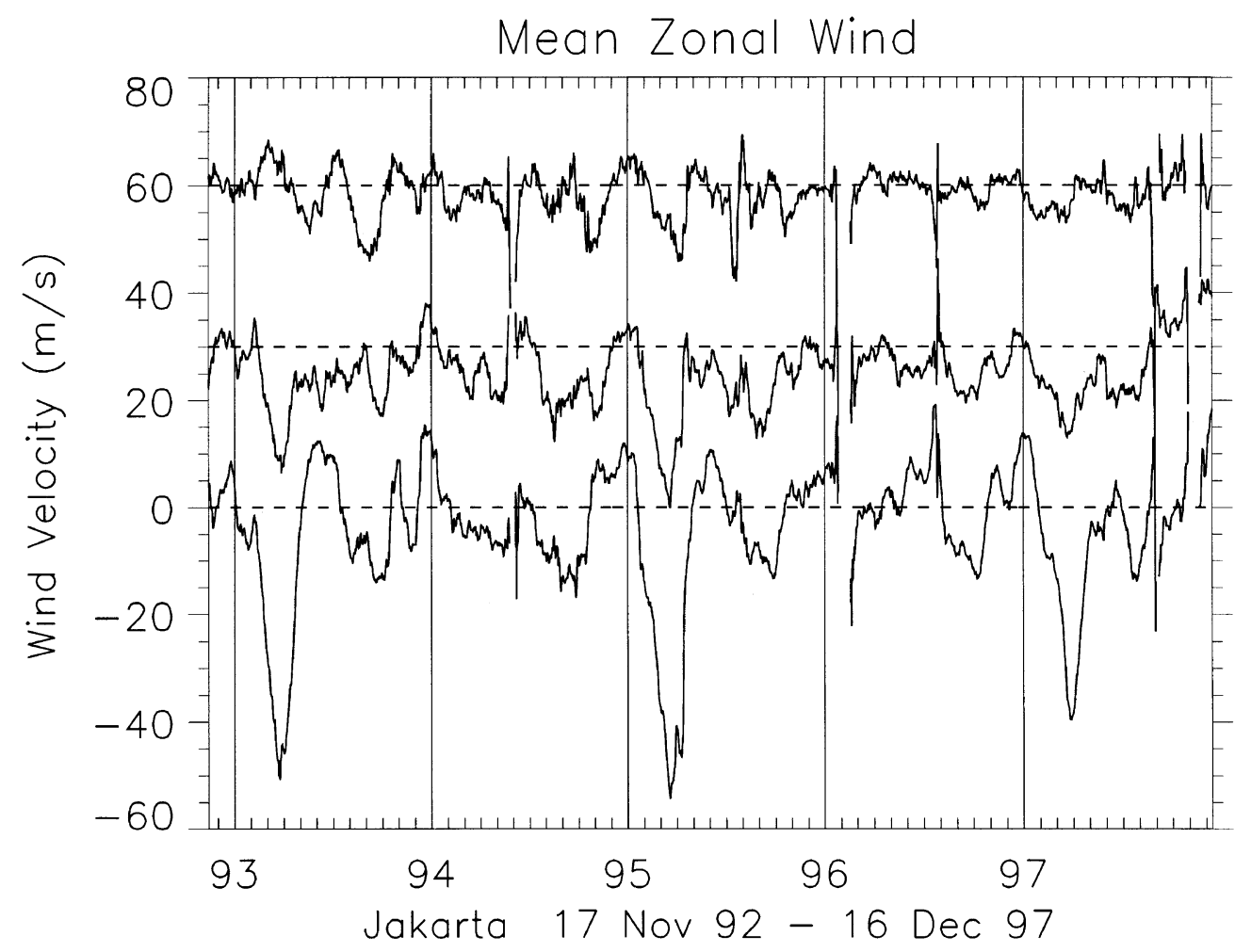

Fig. 2. The 30 days-mean zonal winds over Jakarta at 82-86 km (bottom), 90-94 km (middle) and 98-102 km (top) altitude in 1993-1997. Each plot is shifted by $30 \mathrm{~m} / \mathrm{s}$.

focus on a seasonal variation of UFK waves and its correlation with MSAO.

\subsection{Mean zonal winds}

Figure 2 shows the eastward wind velocity at three altitudes, obtained by applying a smoothing by a 30 days sliding boxcar on the MWR results. The zonal winds regularly change the direction every about three months. Further, the amplitudes of this MSAO during the first half of a year become large every two years, indicating a QBO oscillation in the mesosphere, which was also reported from UARS satellite observations (Burrage et al., 1996). These features of zonal winds in the MLT region were also observed with an MF radar at Christmas Island (e.g., Garcia et al., 1997). Burrage et al. (1996) suggested that the small-scale gravity waves could be a driving source of a QBO oscillation in the mesosphere by refer to Mengel et al. (1995). Mengel et al. (1995) tested this hypothesis by a numerical model assuming a selective filtering of upward propagating gravity waves due to mean wind in the lower atmosphere, and showed that the small-scale gravity waves produces $\mathrm{SAO}$ and QBO structures in the MLT region.

\section{Seasonal Variations of UFK Waves in the MLT Region}

\subsection{Frequency spectrum}

We first analyzed a frequency spectrum of zonal and meridional winds at each altitude, using the wind velocity data obtained with MWR between November 1992 and December 1997. Note that missing data are linearly interpolated.

Figure 3 shows an example of a frequency spectrum at
$82-86 \mathrm{~km}$ in 1993 , where we adopted a 5 percent smoothing window at both sides of each frequency component in order to suppress statistical fluctuations. We can clearly identify in Fig. 3 a spectral peak for a diurnal and semidiurnal tides as well as a quasi-two-day oscillation, consistent with other observations (e.g., Vincent and Lesicar, 1991; Harris and Vincent, 1993, Palo and Avery, 1996). In addition, spectral peaks at 6-7 day and 3-4 day are also detected mainly for the zonal wind components. The 6-7 day wave had been interpreted as a Doppler-shifted 5-day normal mode. However, Meyer and Forbes (1997) recently reported that this wave corresponds to unstable mode ascribed to the strong vertical shear of the mesospheric zonal mean wind field in the middle latitude atmosphere. Kovalam et al. (1999) investigated this 6-7 day wave in detail by using the MF radar data obtained at Christmas Island and Pontianak $\left(0.02^{\circ} \mathrm{S}, 109.3^{\circ} \mathrm{E}\right)$ and showed that the obtained result was consistent with the 6-7 day wave described by Meyer and Forbes (1997). The 3-4 day wave has been identified as a manifestation of a UFK wave propagating eastward at a zonal wavenumber one (e.g., Salby et al., 1984; Vincent, 1993; Lieberman and Riggin, 1997; Riggin et al., 1997). This conclusion has been confirmed by a correlation MF radar study between Christmas Island and Pontianak, Indonesia, which is described by Kovalam et al. (1999).

We have determined a frequency spectrum for the zonal and meridional wind velocity at $82-86 \mathrm{~km}$ altitude, sliding a data segment with a duration of 30 days. We then define the UFK wave energy by integrating the frequency spectral density between $0.25-0.33$ day $^{-1}$ corresponding to a wave 


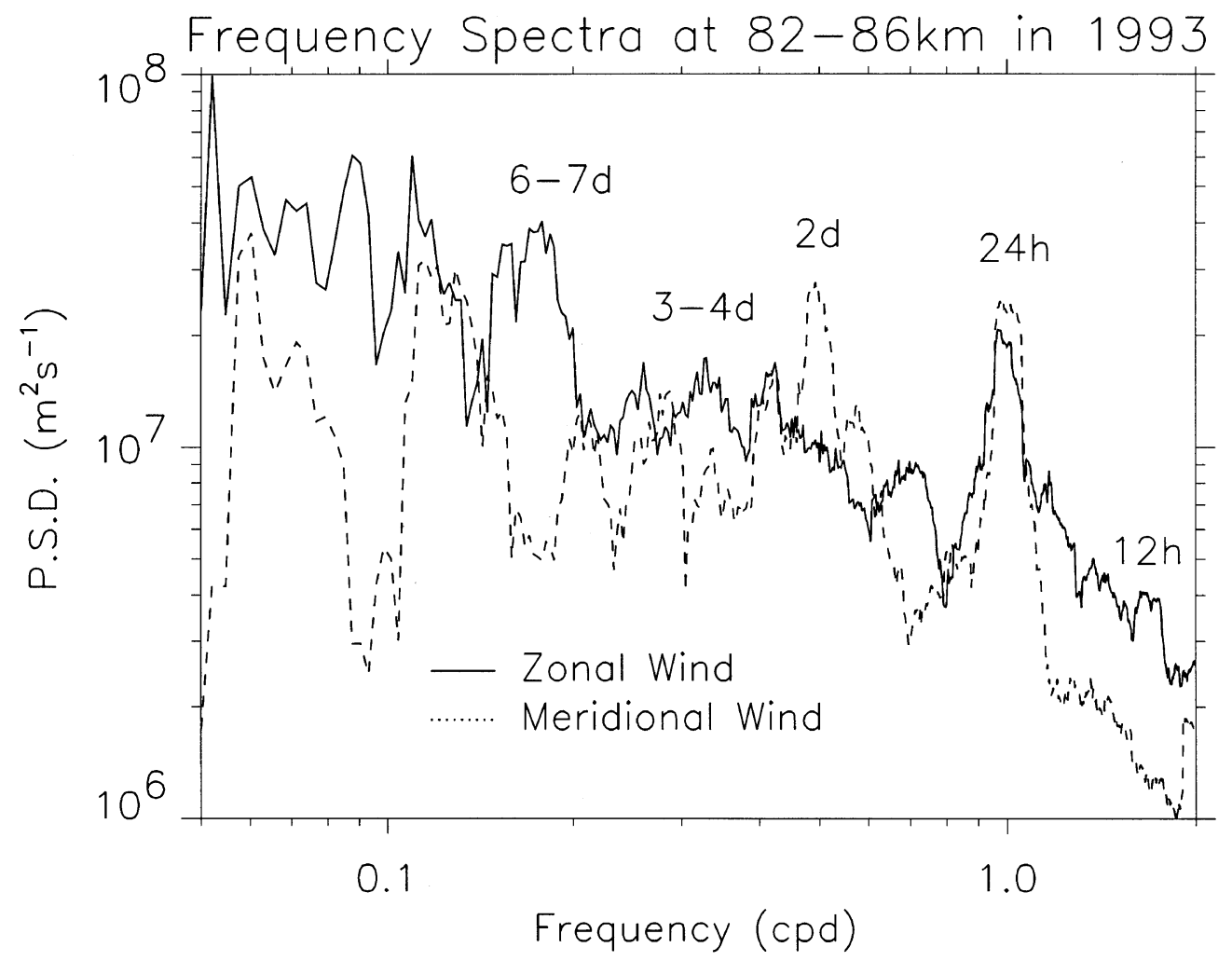

Fig. 3. Power spectral density of zonal (solid line) and meridional (dotted line) wind velocities over Jakarta at $82-86 \mathrm{~km}$ altitude in 1993 . The power spectrum has been smoothed moothing with a frequency window of \pm 5 percent of the central frequency is applied.

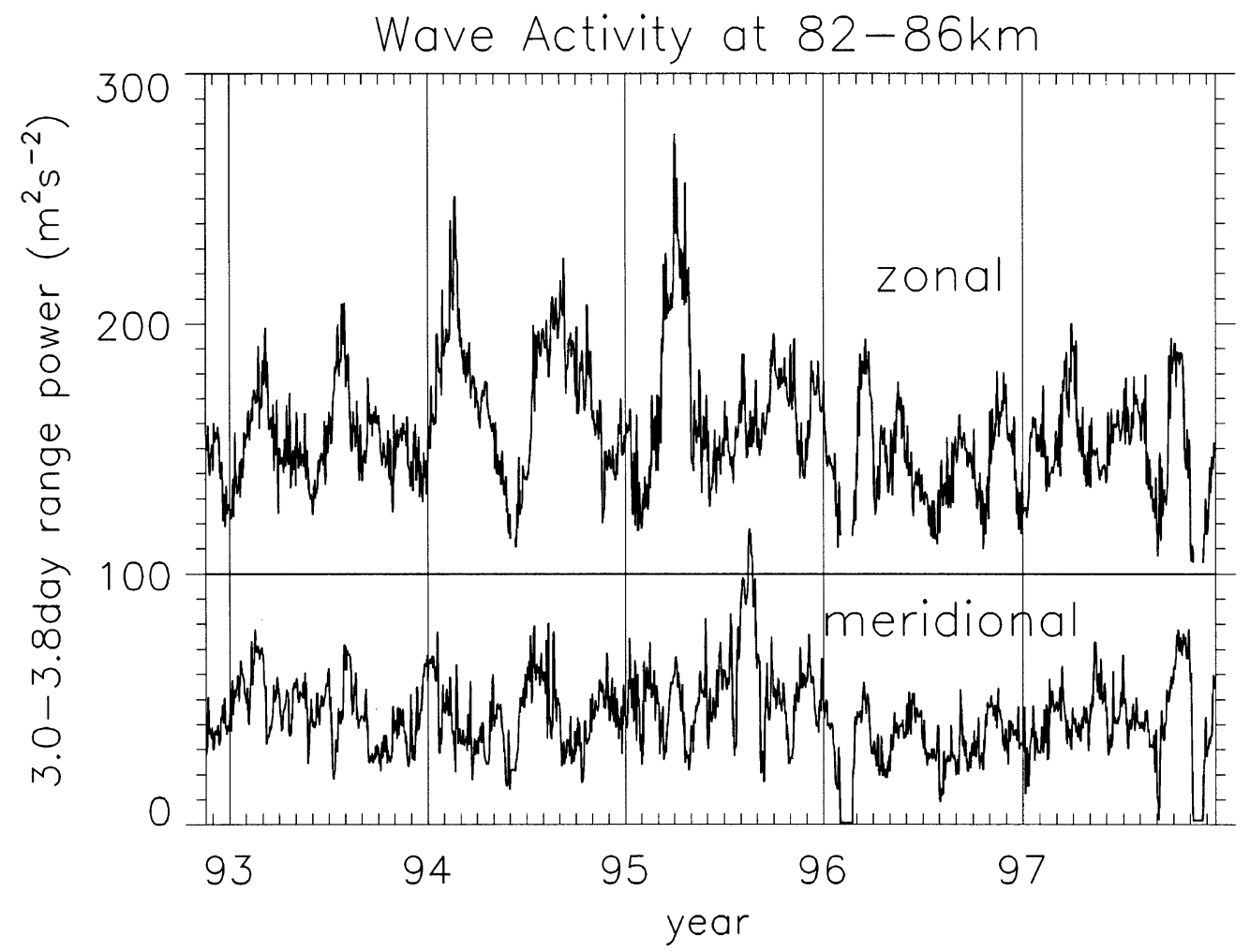

Fig. 4. The time series of the variance of zonal (top) and meridional (bottom) wind at 3.0-3.8 day period range over Jakarta in 1992-1997 at 82-86 km altitude. Each variance is calculated by investigating the P.S.D. of the wind velocities calculated in the data over a 30 days window. 


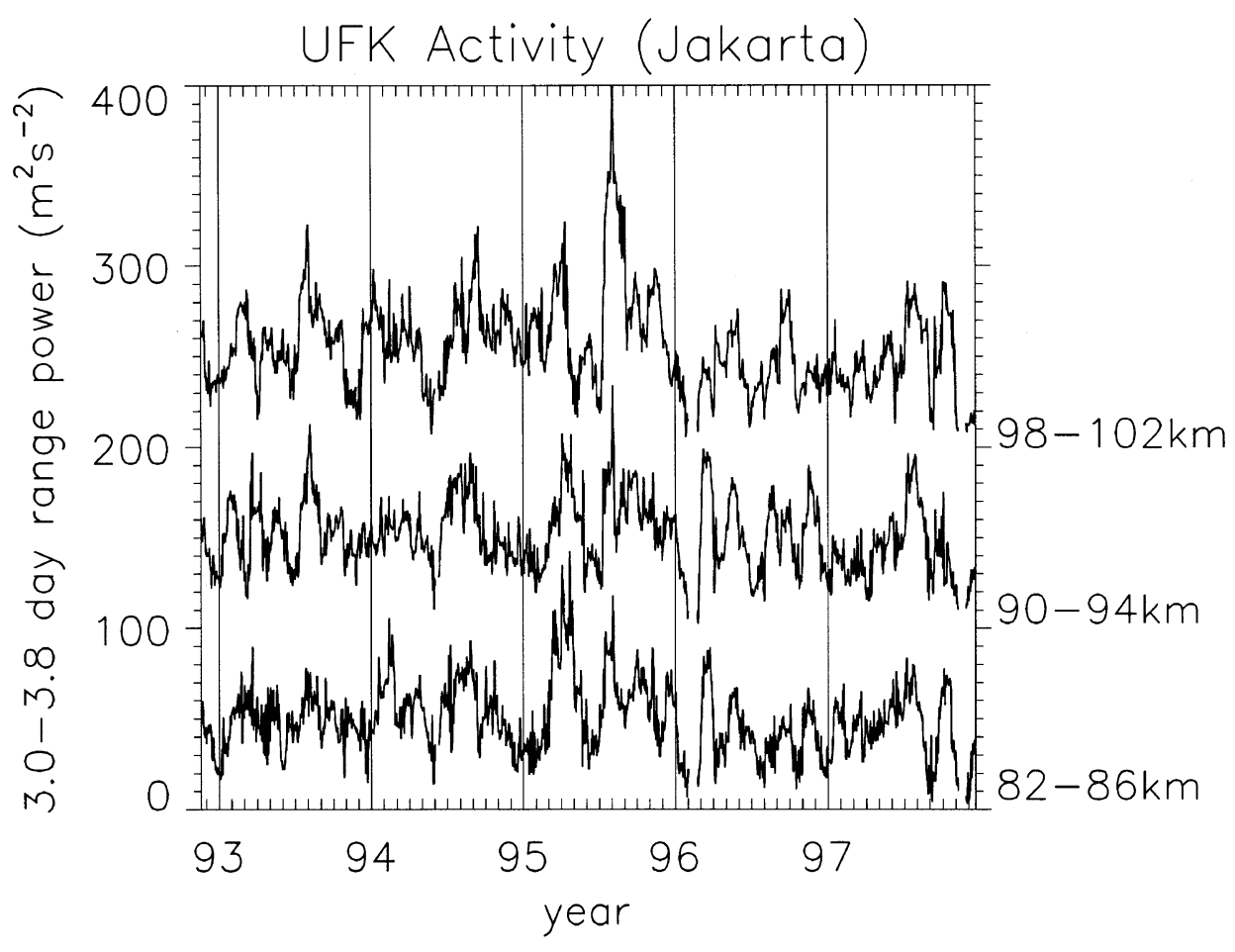

Fig. 5. The time series of the UFK wave activity in 3 layers at $82-106 \mathrm{~km}$, calculated in the same way as Fig. 4 . Each plot is averaged over 3 height points and shifted by $1.0 \times 10^{2} \mathrm{~m}^{2} \mathrm{~s}^{-2}$.

period of about 3.0-3.8 days, Time variation of the UFK wave energy, plotted in Fig. 4, indicates clear enhancements twice a year in 1993-1995, while the semiannual variation was less evident in 1996-1997. The first peak in a year was significantly enhanced in January-March in 1993 and 1994, but in 1995-1997 it occurred a few months later, i.e., in March-May.

The second peak of the year was rather irregular, spreading in July-November. Moreover, the duration of the second peak was longer than four months in 1994 and 1995. It is noteworthy that three peaks were recognized in 1997. The UFK wave energy for the zonal winds was generally much larger than the meridional component, which is consistent with a theory of Kelvin waves. It is also interesting, however, that the seasonal variations show some consistency between the zonal and meridional components in 1993.

Further, we compare in Fig. 5 time variation of the UFK wave activity in the zonal wind for three layers at 82-106 $\mathrm{km}$. Each plot is averaged over three height points, and each indicated altitude is the middle point of averaged height range. The enhancements occurred almost simultaneously in every height range, indicating that the UFK waves propagated vertically through the entire height range during the enhanced activity event, which is consistent with a fact that the UFK waves have a fairly large vertical phase velocity (Salby et al., 1984; Vincent, 1993; Lieberman and Riggin, 1997; Riggin et al., 1997; Kovalam et al., 1999). It is noteworthy that the UFK wave activity shows a semiannual variation even in a higher altitude where MSAO is not dominant anymore. Moreover, effects of the mesospheric QBO does not reflect on the UFK wave activity.

We now investigate a dominant periodicity of the time variation of the UFK wave intensity. Figure 6 shows a frequency spectrum of the time series of the 3.0-3.8 day wave energy at 82-102 km in 1992-97. The most persistent periodicity in Fig. 6 can be detected as a semiannual $(0.0055$ cpd) component. Annual (0.0027 cpd) and biennial (0.0014 cpd) variations are also recognized, although those two periodicity are much less predominant.

We can also find in Fig. 6 a broad enhancement at 0.010.06 day $^{-1}$, corresponding to intraseasonal variations. In particular, the 50-70 day and 20-30 day period ranges were predominant at almost every height ranges. We will discuss in Section 4 a relation of this periodicity with the activity of 30-60 day oscillation in the troposphere (Madden and Julian, 1971, 1972, 1994).

Next, we investigate if the semiannual periodicity can also be recognized for other wave components. Figure 7 presents a time-frequency decomposition of the power in the zonal wind at $82-86 \mathrm{~km}, 90-94 \mathrm{~km}$ and $98-102 \mathrm{~km}$, obtained by sliding the data every 30 days. Spectral density in a wide frequency range between 2 and 10 days, including 3.0-3.8 day components, was enhanced twice a year in 1993-95. Therefore, the semiannual periodicity was not unique for the UFK waves, but it was generally recognized for a wide band of wave frequencies. It is noteworthy, however, that seasonal variations in 1996 and 1997 were different from those in 1993-95. It can be suggested there is a general tendency that various wave activity in the MLT region show a semiannual variation. 


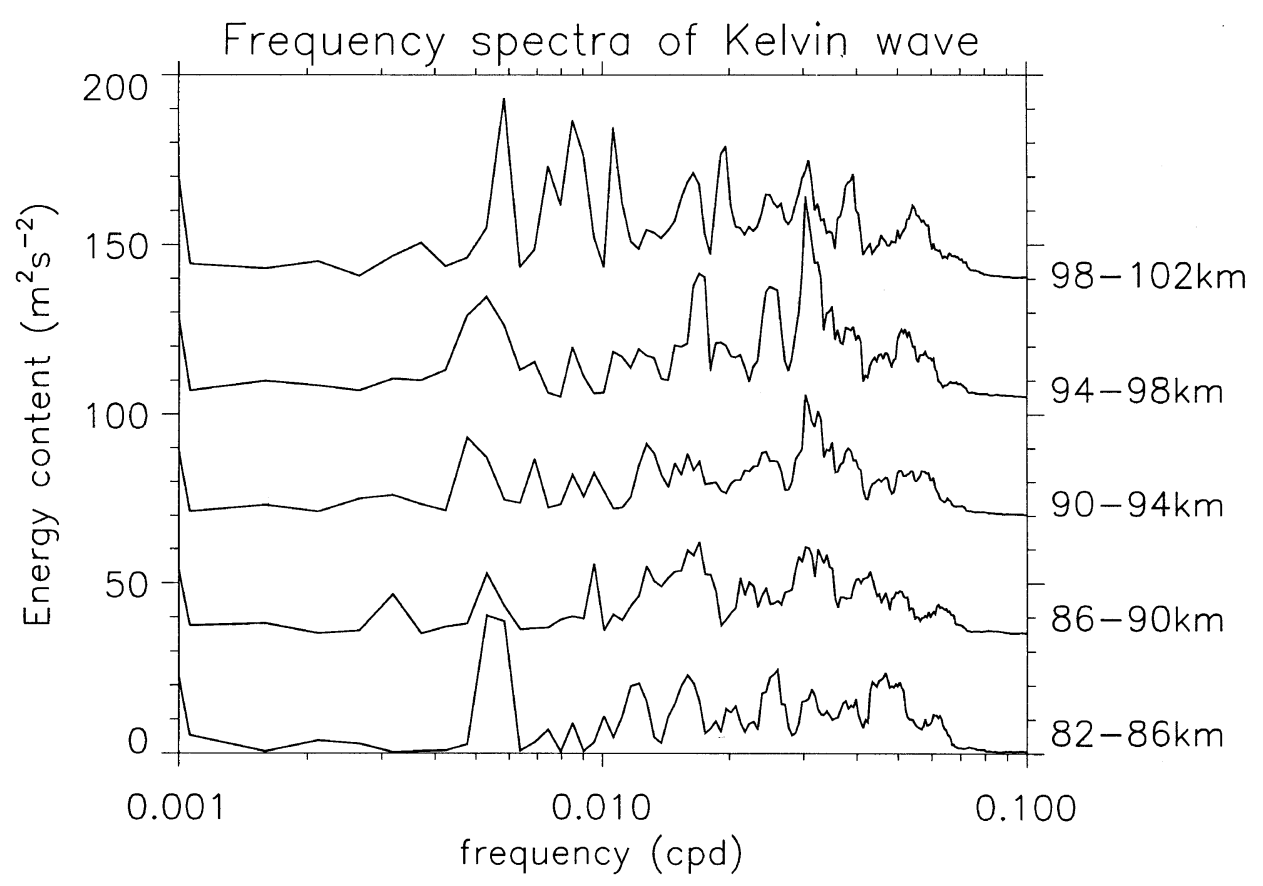

Fig. 6. The frequency spectra of the UFK wave amplitude variations in 6 altitude ranges at $82-106 \mathrm{~km}$. The amplitude of UFK is calculated by applying the 3.0-3.8 day band-pass filter over the whole time series of zonal winds.

\subsection{Relation between UFK waves and MSAO}

We study here a correlation between MSAO and the UFK wave activity, both of them having enhancements twice a year. In order to investigate a detailed correlation between UFK and MSAO, we plot in Fig. 8 the zonal wind as a contour and the UFK wave energy at 82-86 km, 90-94 km and 98$102 \mathrm{~km}$, where the zonal mean winds are plotted as a signed intensity, while the UFK activity is taken from Fig. 5.

The first enhancement of UFK waves in 1993 at $82-86 \mathrm{~km}$ mainly occurred in the westward phase of MSAO. Similar coincidence was recognized at $82-86 \mathrm{~km}$ in 1994-1995, although the period of enhancements is irregular. The UFK wave activity was rather depressed in the eastward phase of MSAO below about $90 \mathrm{~km}$ where MSAO had large amplitudes. But, as the MSAO became weaker above about $95 \mathrm{~km}$, the UFK wave was sometimes enhanced even in the eastward winds, for an example, at 98-102 km in February-May, 1993.

It is reported that the SK wave activity in the lower stratosphere is vigorous in a transition region of QBO from westward to eastward winds (e.g., Wallace and Kousky, 1968). But, the enhancement of UFK waves does not necessarily coincide with the transition of MSAO. So, it is not entirely clear if there exists a correlation between the enhancement of UFK waves and the mean wind direction and/or zonal wind shear. These difference between SK and UFK is naturally attributed to each phase speed.

Moreover, although amplitudes of MSAO exhibit a biennial periodicity, as seen in Fig. 2, the UFK activity did not correlate with the mesospheric QBO. It is concluded that the semiannual periodicity of the UFK wave activity could be attributed to an interaction with the mean winds below the observation range of MWR, i.e., the stratospheric SAO.

\section{Discussion}

\subsection{Radiosonde results of 3.0 $\sim 3.8$-day oscillations in the} lower atmosphere

We analyze here the long-term characteristics of the 3.03.8 day waves in the troposphere and lower stratosphere, using radiosonde measurements of horizontal winds in Bandung, Indonesia. In the background zonal winds, the QBO was dominant above about $18 \mathrm{~km}$ altitude, and the stratospheric SAO superimposed above $35 \mathrm{~km}$.

From a daily radiosonde data, we have obtained a time series of zonal winds at each altitude, and extracted fluctuations by applying a band-pass filter with a pass-band period of 3.03.8 day. Gravity waves could fall in the wave period range of 3.0-3.8 day, since the inertial period is as long as 4.16 days at Bandung. Using similar data-sets of radiosondes, Tsuda et al. (1994a,b) and Shimizu and Tsuda (1997) detected that the vertical wavelength of dominant gravity waves ranged from 2 to $5 \mathrm{~km}$. Therefore, we have further applied a low-pass filter with a cutoff wavelength at $5 \mathrm{~km}$ on the profile of fluctuating components of zonal winds in order to remove a major part of gravity wave energy. Finally, the wind velocity variance is calculated in a height-time bin of $4.2 \mathrm{~km}$ and 30 day.

It is noteworthy that semiannual periodicity of the zonal wind variance was not detected in the stratosphere unlike the case for the UFK wave activity in the MLT region.

\subsection{Intraseasonal variation of the UFK wave activity}

Eckermann and Vincent (1994) observed an intraseasonal variation of zonal winds in the MLT region at Christmas Island. Eckermann et al. (1997) further reported that the intraseasonal variation of the mean winds correlates with the intensity variation of diurnal tides and gravity waves. Lieberman (1998) also detects an intraseasonal variation (20-120 days) in HRDI zonally averaged zonal winds. 

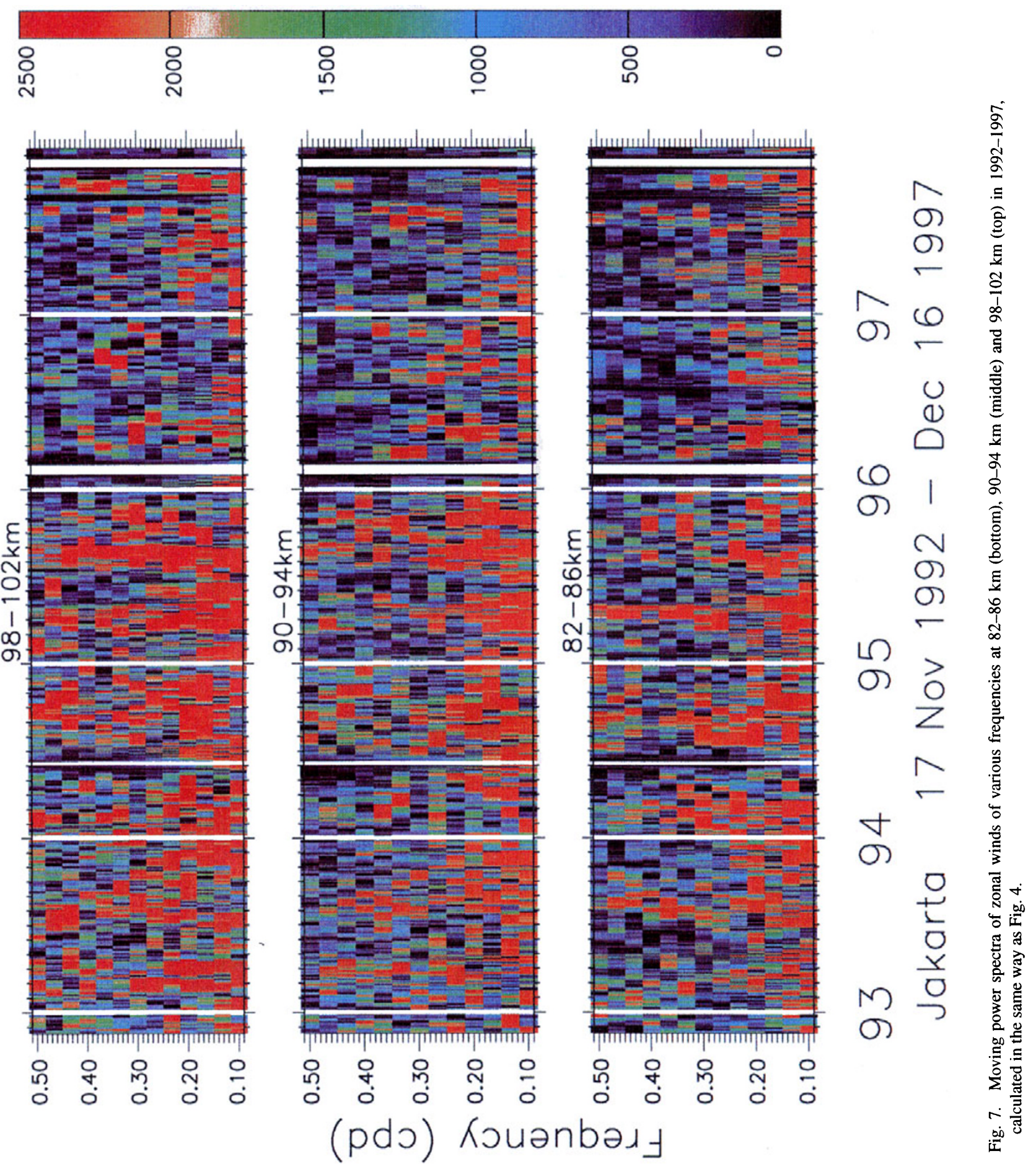

$$
\left({ }_{1-} \mathrm{ZH} \mathrm{S} \mathrm{C} \mathrm{m}\right)(\mathrm{IDUOZ}) \cdot \mathrm{O} \cdot \mathrm{S} \cdot \mathrm{d}
$$




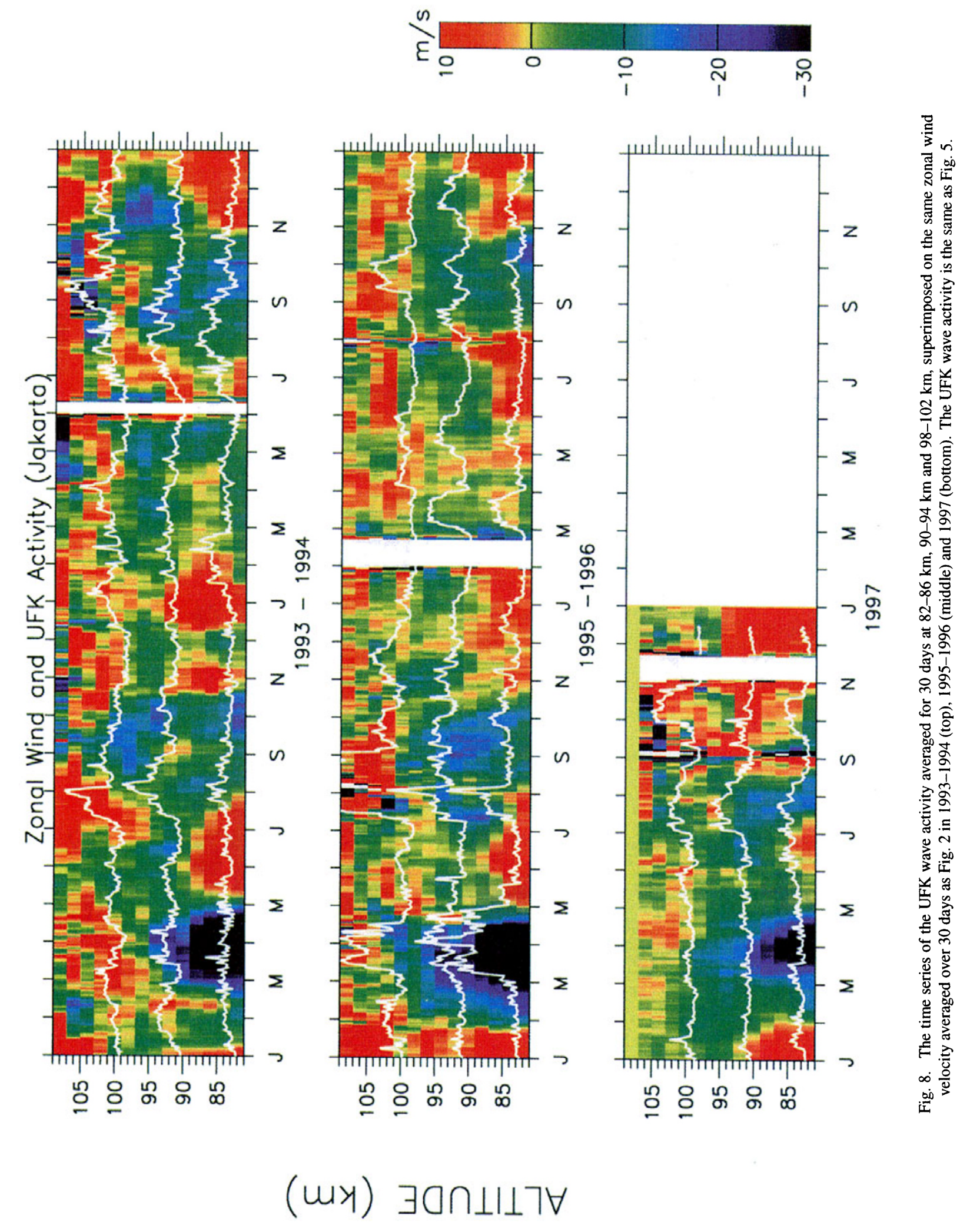




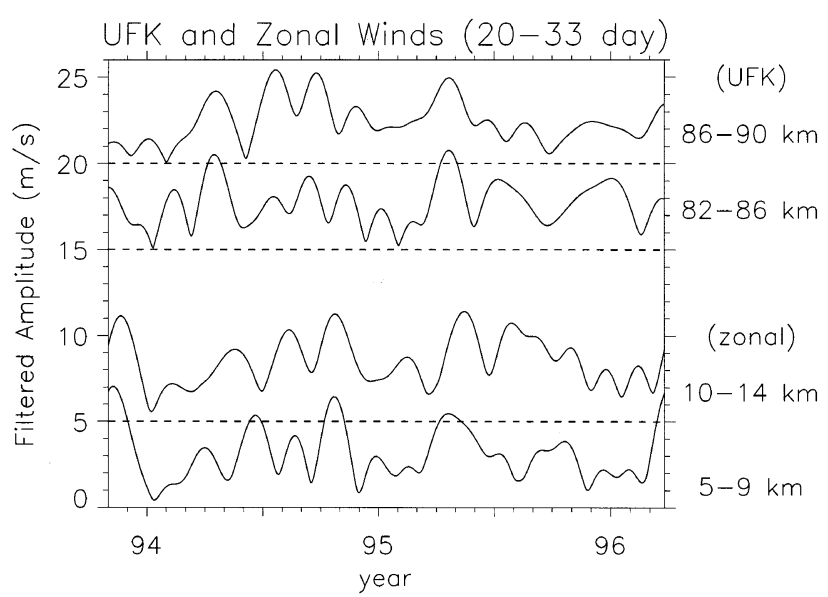

Fig. 9. Amplitudes of fluctuations of UFK waves with a period range of 20-33 days in the MLT region (top lines) and mean zonal winds in the troposphere band-pass filtered with a 20-33 day pass-band (bottom lines) in November 1993-March 1996. Dashed lines indicate "0" level for each plot.

Eckermann et al. (1997) proposed a mechanism that the generation of gravity waves, tides and planetary waves in the lower atmosphere is modulated by a Madden-Julian Oscillation (MJO) (Madden and Julian, 1994), having 30-60 day periodicity. Riggin et al. (1997) reported that UFK waves in the MLT region was enhanced intermittently with a periodicity of about 20 days, and further suggested a connection to an event in the lower atmosphere.

The frequency spectra in Fig. 6 indicate that the UFK wave activity also includes intraseasonal variations, other than the dominant semi-annual component. In particular, a broad spectral enhancement is detected at about 20-30 days and about 50-70 days at every height range. We have delineated an asymptotic variation of the UFK wave activity, smoothing out the 20-33 days $(0.3-0.5 \mathrm{cpd})$ components, as plotted in Fig. 9 at $82-86 \mathrm{~km}$ and $86-90 \mathrm{~km}$ altitudes, together with the absolute value of the eastward wind velocity with 20-33 days components at 5-9 $\mathrm{km}$ and 10-14 km.

Both the UFK wave activity in the MLT region and the zonal winds in the lower atmosphere indicate large amplitudes in June-November 1994. In March-May 1995, similar coincidence can be seen. The event in the MLT region occurred earlier than that in the troposphere by about 25 days. Therefore, a direct correlation may not easily be hypothesized, even if we consider a time lag due to a difference between horizontal motion of $\mathrm{MJO}$ and vertical propagation of UFK waves.

\section{Summary}

In this study, we have analyzed the behavior of the UFK waves observed in the MLT region using MWR data for 1992-1997 at Jakarta. The seasonal variation of UFK wave amplitudes was found to be clearly dominated by a semiannual periodicity, strongly suggesting a relation between the UFK waves and MSAO and/or SSAO. However, the UFK activity did not correlate with a biennial variation of the MSAO amplitudes.

In the lower atmosphere we also investigated the seasonal variation of the 3.0-3.8 day wave from radiosonde profiles for 1993-1996 at Bandung. The 3.0-3.8 day components did not indicate a semiannual periodicity.

We have detected intraseasonal variations (20-33 days) of the UFK wave activity in the MLT region, which shows some correlation with the zonal wind amplitudes in the troposphere.

Acknowledgments. We deeply appreciate help from the staff of LAPAN and BPPT for the construction and operation of the radar near Jakarta and radiosonde experiments in Bandung. We are also greatly indebted to I. Hirota, S. Yoden, K. Sato, N. Nishi, D. M. Riggin, and R. A. Vincent for helpful discussion and comments.

\section{References}

Burrage, M. D., R. A. Vincent, H. G. Mayr, W. R. Skinner, N. F. Arnold, and P. B. Hays, Long-term variability in the equatorial mesosphere and lower thermosphere zonal winds, J. Geophys. Res., 101, 12847-12854, 1996.

Devarajan, M., C. A. Reddy, and C. Raghava Reddi, Rocket observations of Kelvin waves in the upper stratosphere over India, J. Atmos. Sci., 42, 1873-1879, 1985.

Dunkerton, T. J., On the role of the Kelvin wave in the westerly phase of the semiannual zonal wind oscillation, J. Atmos. Sci., 36, 32-41, 1979.

Dunkerton, T. J., The role of gravity waves in the quasi-biennial oscillation, J. Geophys. Res., 102, 26053-26076, 1997.

Ebdon, R. A., Notes on the wind flow at $50 \mathrm{mb}$ in tropical and subtropical regions in January 1957 and January 1958, Q. J. R. Meteorol. Soc., 86, 540-543, 1960.

Eckermann, S. D. and R. A. Vincent, First observation of intraseasonal oscillations in the equatorial mesosphere and lower thermosphere, Geophys. Res. Lett., 21, 265-268, 1994.

Eckermann, S. D., D. K. Rajopadhyaya, and R. A. Vincent, Intraseasonal wind variability in the equatorial mesosphere and lower thermosphere: Long-term observations from the central Pacific, J. Atmos. Terr. Phys., 59, 603-627, 1997.

Garcia, R. R., T. J. Dukerton, R. S. Lieberman, and R. A. Vincent, Climatology of the semiannual oscillation of the tropical middle atomosphere, J. Geophys. Res., 102, 26019-26032, 1997.

Groves, G. V., Annual and semi-annual zonal wind components and corresponding temperature and density variations, $60-130 \mathrm{~km}$, Planet. Space Sci., 20, 2099-2112, 1972.

Harris, T. J. and R. A. Vincent, The quasi-two-day wave observed in the equatorial middle atmosphere, J. Geophys. Res., 98, 10481-10490, 1993.

Hirota, I., Equatorial waves in the upper stratosphere and mesosphere in relation to the semiannual oscillation of the zonal wind, J. Atmos. Sci., 35, 714-722, 1978.

Hirota, I., Kelvin waves in the equatorial middle atmosphere observed by the Nimbus 5 SCR, J. Atmos. Sci., 36, 217-222, 1979.

Hitchman, M. H. and C. B. Leovy, Estimation of the Kelvin wave contribution to the semiannual oscillation, J. Atmos. Sci., 45, 1462-1475, 1988.

Holton, J. R. and R. S. Lindzen, An updated theory for the quasi-biennial cycle of the tropical stratosphere, J. Atmos. Sci., 29, 1076-1080, 1972.

Kovalam, S., R. A. Vincent, I. M. Reid, T. Tsuda, T. Nakamura, K. Ohnishi, A. Nuryanto, and H. Wiryosumarto, Longitudinal variations in planetary wave activity in the equatorial mesosphere, Earth Planets Space, 51, this issue, 665-674, 1999.

Lieberman, R. S., Intraseasonal variability of high-resolution Doppler Imager winds in the equatorial mesosphere and lower thermosphere, J. Geophys. Res., 103, 11221-11218, 1998.

Lieberman, R. S. and D. Riggin, High resolution doppler imager observations of Kelvin waves in the equatorial mesosphere and lower thermosphere, J. Geophys. Res., 102, 26117-26130, 1997.

Madden, R. A. and P. R. Julian, Detection of a 40-50 day oscillation, $J$. Atmos. Sci., 28, 702-708, 1971.

Madden, R. A. and P. R. Julian, Description of global-scale circulation cells in the tropics with a 40-50 day period, J. Atmos. Sci., 29, 1109-1123, 1972.

Madden, R. A. and P. R. Julian, Observations of the 40-50-day tropical oscillation-A review, Mon. Wea. Rev., 122, 814-837, 1994.

Maruyama, T., Long-term behavior of Kelvin waves and mixed Rossbygravity waves, J. Meteor. Soc. Japan, 47, 245-254, 1969. 
Mengel, J. H., H. G. Mayr, K. L. Chan, C. O. Hines, C. A. Reddy, N. F. Arnold, and H. S. Porter, Equatorial oscillations in the middle atomosphere generated by small scale gravity waves, Geophys. Res. Lett., 22, 3027-3030, 1995.

Meyer, C. K. and J. M. Forbes, A 6.5-day westward propagating planetary wave: origin and its characteristics, J. Geophys. Res., 102, 26173-26178, 1997.

Palo, S. E. and S. K. Avery, Observations of the quasi-two-day wave in the middle and lower atmosphere over Christmas Island, J. Geophys. Res., 101, 12833-12846, 1996.

Reed, R. J., Some features of the annual temperature regime in the tropical stratosphere, Mon. Wea. Rev., 90, 211-215, 1962.

Riggin, D., D. C. Fritts, T. Tsuda, T. Nakamura, and R. A. Vincent, Radar observations of a 3-day Kelvin wave in the equatorial mesosphere, $J$. Geophys. Res., 102, 26141-26157, 1997.

Salby, M. L., D. L. Hartmann, P. L. Bailey, and J. C. Gille, Evidence for equatorial Kelvin modes in Nimbus-7 LIMS, J. Atmos. Sci., 41, 220-235, 1984.

Shimizu, A. and T. Tsuda, Characteristics of Kelvin waves and gravity waves observed with radiosondes over indonesia, J. Geophys. Res., 102, 26159-26171, 1997.

Shiotani, M. and T. Horinouchi, Kelvin wave activity and the quasi-biennial oscillation in the equatorial lower stratosphere, J. Meteor. Soc. Japan, 71, 175-182, 1993.

Tsuda, T., Y. Murayama, H. Wiryosumarto, S. W. B. Harijono, and S. Kato, Radiosonde observations of equatorial atmosphere dynamics over in- donesia Part1: Equatorial waves and diurnal tides, J. Geophys. Res., 99, 10491-10505, 1994a.

Tsuda, T., Y. Murayama, H. Wiryosumarto, S. W. B. Harijono, and S. Kato, Radiosonde observations of equatorial atmosphere dynamics over indonesia Part2: Characteristics of gravity waves, J. Geophys. Res., 99 104507-10516, 1994b.

Tsuda, et al., A preliminary report on observations of equatorial atmospheric dynamics in Indonesia with radars and radiosondes, J. Meteor. Soc. Japan 73, 393-406, 1995.

Vincent, R. A., Long-period motions in the equatorial mesosphere, J. Atmos. Terr. Phys., 55, 1067-1080, 1993.

Vincent, R. A. and D. Lesicar, Dynamics of the equatorial mesosphere: First results with a new generation partial reflection radar, Geophys. Res. Lett., 18, 825-828, 1991.

Wallace, J. M. and V. E. Kousky, Observational evidence of Kelvin waves in the tropical stratosphere, J. Atmos. Sci., 25, 900-907, 1968a.

Wallace, J. M. and V. E. Kousky, On the relation between Kelvin waves and the Quasi-biennial oscillation, J. Meteor. Soc. Japan, 46, 496-502, $1968 b$.

Yanai, M. and T. Maruyama, Stratospheric wave disturbances propagating over the equatorial Pacific, J. Meteor. Soc. Japan, 44, 291-294, 1966.

S. Yoshida (e-mail: yoshida@kurasc.kyoto-u.ac.jp), T. Tsuda, A. Shimizu, and T. Nakamura 
Fig. 7. Moving power spectra of zonal winds of various frequencies at 82-86 km (bottom), 90-94 km (middle) and 98-102 km (top) in 1992-1997, calculated in the same way as Fig. 4.

Fig. 8. The time series of the UFK wave activity averaged for 30 days at 82-86 km, 90-94 km and 98-102 km, superimposed on the same zonal wind velocity averaged over 30 days as Fig. 2 in 1993-1994 (top), 1995-1996 (middle) and 1997 (bottom). The UFK wave activity is the same as Fig. 5. 